\title{
A Strategy towards Inclusive Education in the 21 Century: A Case of Gauteng, South Africa
}

\author{
Dikeledi Mahlo \\ Department of Inclusive Education \\ University of South Africa, PO Box 392 Pretoria 0003 \\ mahlofd@unisa.ac.za
}

\section{Doi:10.5901/mjss.2013.v4n13p37}

\begin{abstract}
Of the numerous changes that have taken place in the education system of South Africa since the inception of universal suffrage in 1994, one is the introduction of inclusive education, practice which aims to respond to the educational needs of all learners, irrespective of their differences. The national Department of Education (DoE) suggested a number of strategies for the effective implementation of Inclusive Education. In Gauteng Province specialist teachers are employed in primary schools specifically to provide support to classroom teachers and learners. Guided by Bronferbrenner's ecological model and using qualitative research methods data was collected from seven Learning Support Teachers in seven schools. From the data analyzed using Tesch's method, the findings revealed that with the necessary parental, emotional and financial support, inclusive education can be implemented effectively. However, this paper focuses on the support that can be given at district level, and concludes that with it the Learning Support Teachers can be an important component of a strategy for implementing Inclusive Education in the 21st century.
\end{abstract}

Keywords: Learning Support Teachers, Strategy, Support, Inclusive Education, Barriers to learning.

\section{Introduction}

The policy of inclusive education (IE) sanctioned in White Paper Six (WP6, 2001) required teachers to accommodate all learners with diverse needs. Some had intrinsic barriers, others extrinsic, yet all were to be accommodated in the same classroom. Teachers in South Africa generally do not cover barriers to learning in their initial teacher education training and therefore find it difficult when confronted by them. To bridge the gap, Gauteng is using Learning Support Teachers (LSTs), as specialist teachers trained in IE, learning support or remedial education.It is important to recognize that inclusivity is complex, but it should not be seen as an issue of placing learners with diverse needs and barriers in regular classes, without the appropriate support. In this case, the LSTs are one kind of support but their needs are catered for by the system and whoever interacts with them. They are part of a model of holistic development, modifying and adapting teacher attitudes to enable all learners to engage fully with the curriculum.

Florian and Rouse (2010:190) maintain that most mainstream teachers do not believe that they have the skills or knowledge to teach learners with learning barriers because they have not taken a specialist course. Furthermore, they believe there are experts 'out there' to teach those learners on a one-to-one basis and therefore teaching them is not their responsibility. This type of thinking becomes a barrier to IE, as developing effective inclusive practices is not only about extending teachers' knowledge but also encouraging them to do things differently and to reconsider their attitudes and beliefs. Objective realities include changes in teaching style, resource and skills. These are many variables that can impact on a school's effectiveness in the implementation of inclusive education as it attempts to address the diverse needs of learners. Educational change has to be considered from the teacher's perspective.

Forlin (2004:13) asserts that IE is not only a new paradigm that has its own language, but actually challenges traditional attitudes, beliefs and understanding of inclusion. In this study, it is seen as challenging the traditional way in which education is organized, with the classroom teacher no longer the only person who teaches the learner. If the learner experiences a barrier that the teacher is unable to handle, a specialist can be contacted, in this case the LST. The practice raises issues of teachers being comfortable in their own classrooms, with the LSTs being perceived as advisors on teaching methods and/or providers of programmes to assist learners with barriers. This supports one of the principles outlined in the WP6, (DoE (2001:16), namely that IE is about changing attitudes, behavior, teaching methodologies, curricula, and the environment to meet the needs of the learners. 
Collaboration between the teacher and the LSTs is important because the latter have the skills relevant to supporting learners with barriers. Teachers should try to teach learners the ways in which they can learn, by using different ways of teaching, as learners have different learning styles. Foundation Phase teachers should be empowered with effective teaching strategies in order to lay a good foundation for learners.

\title{
1.1 Theoretical Framework
}

The theoretical framework that informed the study is the ecological perspective of Bronferbrenner (1979:21), which affirms a vision of IE:

\begin{abstract}
... Ecology of Human Development involves the scientific study of the progressive, mutual accommodation between an active, growing human being and the changing properties of the immediate settings in which the developing person lives, as this process is affected by relations between the settings, and by the larger context in which the settings are embedded.
\end{abstract}

The ecological perspective demonstrates how a micro-system, for example the home, is interwoven with the meso-system, for example the school, as well as the wider society, in determining the level of comfort and contentment human beings experience as they go about their life courses. The theory also explains the differences in the individual's knowledge, skills and abilities and the role of a support system to guide and structure the individual. The overlapping micro-, meso-, exo- and macro-systems all contribute to form the whole that the individual will perceive as positive or negative (Haihambo, 2010:65).

The system of education could be a representative of various micro-systems that form the meso-system in this study, for instance teachers, district, school environment, provincial departments, support, and resources that might be significant in explaining the experiences, attitudes, frustrations and motivation for LSTs to execute their duties. The theory was suitable for understanding their experiences.

\section{Inclusive Education in the $21^{\text {st }}$ Century in South Africa}

IE and Training System policy (2001:16) acknowledges that all children can learn, and that all learners are different, with different needs. Significantly, IE is now deemed appropriate as it can provide various levels and kinds of support to all learners. It is stipulated in the WP6 that support services be strengthened at the institutional, district, provincial and national levels. Recent policy documents in South Africa propose that support systems take a systematic approach, utilizing district support teams that focus on management and personnel support rather than providing direct face-to-face intervention for individual learners (Swart, Engelbrecht, Eloff, Pettipher \& Oswald, 2004:21). Schools need to provide support in a natural setting, thereby minimizing the likelihood of separating children with difficulties from their peers, as well as reducing stigmatization (Naidu, 2007:3). This implies that support services are important in a process of social transition, and need to be integrated into current mainstream structures.

One strategy in the development of a single IE system in South Africa in the $21^{\text {st }}$ century is the Draft National Strategy on Screening, Identification, Assessment and Support (SIAS). This targets all learners in urban and rural settings who need support, not only learners with disabilities, specifically those from the poorest communities in townships, informal settlements or rural areas, as they have previously suffered from unavailability of access to services (DoE, 2005:3). This strategy outlines the role of teachers, especially in the Foundation Phase, parents, managers and support staff within the new framework of how support should be organized. The teachers should identify learners experiencing barriers to learning as early as possible within their phase and give necessary support, observing them carefully in all subjects ('learning areas') so that necessary adaptations can be made.

The SIAS document is thus clear on which learners could be in need of support. It is affirmed that previously the responsibility of assisting learners with barriers to learning lay with specially qualified personnel employed either by educational support services or special schools. Teachers and schools therefore did not view them as their responsibility, but rather deemed it necessary only to identify and refer them. The LSTs in this situation are important as they provide assistance in areas education support services personnel cannot reach.

Classroom teachers now have a responsibility towards learners with diverse needs since they are being educated in the mainstream classes. Giangreco, Carter, Doyle and Suter (2010:251) acknowledge that support provided to classroom teachers is essential, and although classroom teachers are not expected to have all the answers or undertake the task of IE alone, they must realize that while the foundational principles of teaching and learning do not change they 
may need to be applied differently or used more systematically.

Singal (2010:52) maintains that even when children with disabilities do attend the mainstream classrooms teachers do not always regard them as their primary responsibility. This is contrary to the guiding principle underpinning inclusion, that regular schools should accommodate all learners regardless of their physical, intellectual, sensory, emotional or other special needs (Forlin, 2008:76). They should therefore have appropriate skills and as such the expectations on teachers are greater.

\section{Methodology}

The study sought to investigate the experiences of LSTs in the implementation of IE in Gauteng by asking the following research questions:

- What are the experiences of LSTs in the Foundation Phase with reference to implementation of IE in Gauteng?

- What are the factors affecting this implementation?

- What strategies could be used to enhance it?

The researcher aimed to understand people's perceptions, perspectives and understanding of a particular situation, in this case the experiences of the LSTs, therefore phenomenology and qualitative research methods were considered appropriate.

Purposeful sampling was applied to select seven LSTs who on the basis of experience had been working from 2006. It was assumed that they would yield the most relevant information about the topic under investigation (Morse \& Richards, 2002:20). Those currently assisting teachers in the implementation of IE in primary schools were approached, especially in the Foundation Phase (Grade R- Grade three), regarded as the critical stage for promoting an interest in education and developing positive attitudes towards school. If the child fails at this stage she or he may be affected in her or his whole schooling (Joshua, 2006:10).

\subsection{Data collection}

Interviews, observations and document analysis were used to capture the data. One-to-one interviews not exceeding one hour were conducted in English after working hours until data saturation was reached. Observations of LSTs supporting learners and classroom teachers were made and field notes taken. Observations were included as a research technique of obtaining data because the researcher wished to gather data from the natural setting, i.e., the classroom. Document analysis entails scrutiny of relevant documents, which can be a valuable source of information (Henning, Van Rensburg \& Smit. 2004:99), which in the current study gave the researcher an idea of the challenges and successes of LSTs in the Foundation Phase. They are also valuable sources for supporting the findings made through other research methods, such as interviews and observations (Best \& Kahn, 2006:201).

\subsection{Data analysis}

Qualitative data analysis takes place throughout the data collection process, the researcher reflecting constantly on impressions, relationships and connections. According to Bassey (2002:84), the process is an "intellectual struggle" with the raw data collected. The verbatim accounts of the interviews were transcribed, different categories relating to the research topic formed and information from interviews, observations and document analysis analyzed and arranged according to themes.

The researcher started by transcribing the data through making a text from taped interviews, observations and documents, and typing them as word processing documents. Data was analyzed using Creswell's method of data analysis. The process commenced by reading all the data then dividing it into smaller meaningful units. Data segments or units were then organized into a system predominantly derived from the data, and comparisons used to build and refine categories which were then modified (Creswell, 2002:150). The respondents were identified as 'Respondents A-G' in the study, with their true identity remaining known only to the researcher.

\section{Findings}

Support can be defined as all activities that increase the capacity of a school to respond to diversity. The Gauteng 
Department of Education (GDE) demonstrated its commitment to addressing the barriers of learners by employing LSTs to address those issues which the district officials could not reach. Support is provided on issues of curriculum and institutional development to ensure that the teaching and learning framework is responsive to the full range of learning needs. Where necessary, LSTs provide direct learning support to learners where the Institutional Level Support Team (ILST) is unable to respond. The challenge is mainly the needs of the LSTs that are not met, in order for them to fulfill their duties effectively. If the LSTs are not assisted continuously while implementing this particular policy (IE), the vision of IE may not be realized. It is clear from the analyses of data that LSTs are willing and trying to fulfill their duties by supporting teachers and learners so that those who are experiencing barriers to learning can benefit. However, most of the time they are discouraged by lack of support necessary for LSTs if they are to meet their obligations. According to WP6, support for teachers and learners should be provided by the District-based Support Team (DBST).

The DBST is responsible for providing a coordinated professional support service to the schools, ILSTs, teachers and learners, however a lack of support was evident in the words of LST G: "We need support from the district, if the district can be seen more frequently, if they can see that the district officials more frequently, jaa, and if people can be may be charged I don't know how because they don't take me seriously, things are done". The district is supposed to support teachers, but, according to the respondents this was not happening. Echoing the sentiments, LST G said: "They don't take this seriously, because the district itself don't take it seriously also, we only have one cluster meeting in three months and the last time we had a meeting of the SBST was second quarter last year [2009], we only had two for the whole year last year so there is no seriousness, even in the district there is no seriousness, even the district officials they only know us when they feel like they don't want to go somewhere, and then they will phone you and say go and do that for us, it's not fair". Analysis of the above statements reveals that the support for LSTs in this district is not meeting their expectations.

Most respondents concurred that they were not receiving adequate support from the districts in terms of collaboration within units in the districts. They said that different units in the district did not understand their role in schools, as stated by LST E: "The problem is the other district official from the other units, they don't understand what we do at schools". LST A shared the sentiments: "Officials that are not doing inclusion they don't even recognize us, they think we are not important like them." LST D agreed: "We need to have a meeting with district people so that we can explain what we do at schools, it seems they don't know and they don't even care". Similarly, for LST B: "We don't even have an office at the district, how will they take us seriously? We are not one of them". All the above LSTs indicated that they were not recognized or acknowledged by district officials mainly from the other units, because they did not know or understand their roles in schools.

All respondents interviewed shared the view that teachers looked down on them and that other units in the district did not even acknowledge their existence. LST E voiced a particular concern: "They will tell you that you are an LST, we are having the curriculum people who want the curriculum to be finished". This was affirmed by G: "They will tell you when we are going to implement those strategies district curriculum people will want activities in a term". This indicates that IE was not being given the priority afforded the other activities in the school, so was not taken seriously. According to the teachers, they would rather do what the curriculum officials told them to do, and let IE follow later.

Four of the LSTs agreed that support was necessary for teachers and learners for IE to succeed. They felt that LSTs were not receiving adequate support and they were concerned that this was going to affect the implementation of IE as well as learners who were supposed to benefit from it and succeed in their academic careers. This was affirmed by the words of LST E: We are dealing with the curriculum people and they are district officials and who need their work to be done in this way and then when you come with yours they put it aside, they do the work of people who are recognized who are known as district officials". This was further stated by LST C: "It is a challenge because district people also don't know because they are not supportive". In addition, LST F argued that: "They can't waste time to teach a few learners, when the district comes, they monitor activities that are done in class so they want quantity not quality".

This reveals a weakness in the way monitoring and evaluation was being carried out at district level. The teachers were skeptical and felt that quality was being sacrificed to quantity that is, measuring how many activities the learners had done during a particular set time rather than assessing whether they had mastered the subject matter. From these responses it can be deduced that learners experiencing barriers were not being effectively attended to.

LST C said that: "Reporting is not a regular thing, at times they ask for the report, at times they don't, at times we phone and tell them about the progress in our work, so nobody is responsible, there is a problem with the system". This statement confirms the findings in the interviews that the LSTs' work was not being monitored or evaluated, so they asked why they should write reports. The above statement was affirmed by the documents analyzed, that is the LSTs' weekly timetables, from which the following was revealed: 
- LST A: Every week she planned ahead and informed the schools that she would be coming. The coordinator of the ILST prepared the learners and the teachers. She visited mostly two schools which were next to her house. This was evident from all her timetables, since the two schools were visited three times every month, whereas the others were visited once a month. This implies that the two schools were preferred to the others. It will be interesting to see if all the schools receive the same number of visits from the LST. There was no evidence of a district official's signature or stamp to show that the timetables had been checked, meaning that the Inclusion and Special Schools (ISS) officials did not know where the particular LST was working at any time. This is contrary to what was stated in the WP6, namely that districts should evaluate through supporting teaching (DoE, 2001:47).

- LST G: Every week she sent her timetable to various principals of the schools she was serving. She adopted this strategy after realising that at the district level no one cared about her timetables. This indicates that the district needs to strengthen its monitoring and evaluation task. According to this LST it was not the case.

- LST E: She planned what she was going to do the following week, but that plan in most cases did not work because she dealt mostly with crisis management. She mentioned that the district people would call her to drop everything and attend to an emergency, in most cases social problems. One can conclude that the LSTS were acting as social workers for the schools.

- LST D was inconsistent in the writing of her timetables. When her file was checked some of the weeks had been completed but others not. When asked if there was a specific reason for this she said that at first she had been motivated to do the planning but of late she did it only when she could, simply because no one looked at them, whether they were done or not. Districts should be consistent in their evaluation and monitoring procedures, otherwise the LSTs will do as they wish.

From all the documents analyzed it is also clear that there was no uniformity in how the LSTs planned and reported, even though they were working in the same district. Furthermore, the finding reveals inconsistency, with sometimes timetables being written and sometimes not. This finding from the documents was affirmed by the interviews below.

LST G said that "We need support from the district, if the district can be seen more frequently, if they can see that the district officials more frequently here, jaa, and if people can be may be charged I don't know how because they don't take me seriously, things are not done". If a teacher does not treat the issue of inclusion seriously, action should be taken against that teacher, because if one is unable to identify a learner during that early age it might affect him or her for the rest of his or her life.

The Inclusive and Special Schools (ISS) unit, which is a part of the curriculum section at the district, exists to support teachers and learners who experience barriers to learning and development. However, according to the respondents this is not happening. LST A complained: "... they are not supportive, they are not monitoring us, and the only time when they need us is when they are having pressing issues". This was echoed by LST C: "I think if the district plays their role in implementing this inclusion and involvement of the principals, you can see that it has weight?" Because district personnel are well respected at the schools in Gauteng, they can influence the teachers and the principals to practice inclusion. These statements and the discussion in this section confirm the inadequacy of the support offered by the districts, as the LSTs need to have continuous and effective support from the district. They are a valuable resource to the schools.

\section{Discussion}

It is noted that the districts implement the policy according to their different needs. However, all LSTs feel that they are inadequately supported by the district in terms of monitoring and motivation. Inadequate support from the district was strongly emphasized by LSTs who believed that if they could be appropriately supported during the implementation of IE they would not feel isolated or neglected.

The policy on IE draws attention to the importance of strengthening education support services as the DoE believes this is the key to reducing barriers to learning within all education and training. As such, the DBST should provide a full range of education support services, such as professional development in curriculum and assessment to the institutional level support teams. This includes teachers and LSTs. This study found that LSTs are experiencing frustration and helplessness as district officials do not monitor or evaluate to check if they are doing what they are supposed to do. However, the DBST, as emphasized by the policy on IE, is not yet functional in the way it was set out, therefore LSTs are not receiving adequate support from the district. 


\section{Conclusion}

An inclusion policy lays the foundation for all classrooms to become inclusive areas of learning and teaching. Furthermore the inclusive learning environments demonstrate a value system by which all learners feel a sense of belonging and are accepted regardless of their different needs. LSTs in Gauteng are assisting schools in the implementation of IE, as they address the social, physical, emotional and educational needs of learners. However, the implementation seems to be a challenge when they try to provide educational programmes for all learners. The LSTs should be appropriately utilised to fulfil their purpose if the vision of IE is to be realised. It is therefore recommended that monitoring and evaluation be strengthened at the district level. The district needs to strengthen its support strategies for inclusion to succeed.

\section{References}

Bassey, M. (2002). Case study research, in M Coleman \& ARJ Briggs (eds). Research methods in educational leadership and management. London: Paul Chapman, 108-121.

Best, J.W. \& Kahn, J.V. (2006). Research in education. Tenth edition. Boston: Pearson Education Inc.

Bronfenbrenner, U. (1979). Ecology of human development: experiments by nature and design. Cambridge: Harvard Press.

Cresswell, J.W. (2002). Qualitative enquiry and research design. London: Sage.

Department of Education. (2001). Education White Paper 6: special needs education - building an inclusive education and training system. Pretoria: Government Printers.

Department of Education. (2005). Draft National Strategy on screening, identification, assessment and support. Pretoria: Department of Education.

Florian, L. \& Rouse, M. (2010). Teachers' professional learning and inclusive practice, in R Rose (ed). Confronting obstacles to inclusion: international responses to developing inclusive education. London: Routledge:185-200.

Forlin, C. (2004). Incorporating diversity in all schools. Keynote address presented at the International Conference of The South African Association for Learning and Educational Differences, September 2004. Johannesburg: University of Witwatersrand:1-15.

Forlin, C. (2004). Promoting inclusivity in Western Australian schools. International Journal of Inclusive Education 8:185-202.

Forlin, C. (2008). Education reforms for inclusion in Asia: what about teacher education? In C. Forlin and M.G.J. Lian (eds). Reform, inclusion and teacher education: towards a new era of special education in the Asia-Pacific region. Abingdon: Routledge: 74-82.

Giangreco, M.F., Carter, E.W., Doyle, M.B. \& Suter, J.C.(2010). Supporting students with disabilities in inclusive classrooms, in R Rose (ed). Confronting obstacles to inclusion: international responses to developing inclusive education. London: Routledge: 247-264.

Haihambo, C.K. (2010). Inclusive education: challenges of students with disabilities in institutions of higher education in Namibia. DEd thesis, University of South Africa, Pretoria.

Henning, E., Van Rensburg, W. \& Smit, B. (2004). Finding your way in qualitative research. Pretoria: Van Schaik.

Joshua, J.J. (2006). Handbook of research in trans-Atlantic antitrust. Edited by P Marsden. Cheltenham: Edward Elgar.

Morse, J.B. \& Richards, L. (2002). README first for a user's guide to qualitative methods. London: Sage.

Naidu, S. (2007). The changing role of a remedial teacher to a support teacher: a case-study of a primary school in Pinetown. MEd dissertation, University of KwaZulu-Natal, Durban.

Singal, N.( 2010). Including 'children with special needs' in the Indian education system: negotiating a contested terrain, in R Rose (ed.). Confronting obstacles to inclusion: international responses to developing inclusive education. London: Routledge: 45-57.

Swart, E., Engelbrecht, P., Ellof, l., Pettipher, R. \& Oswald, M. (2004). Developing inclusive school communities: Voices of parents of children with disabilities. Education as a Change 8:80-108. 